\title{
A polymer-based spiky microelectrode array for electrocorticography
}

\author{
Gergely Márton, Marcell Kiss, Gábor Orbán, Anita Pongrácz, István Ulbert
}

\begin{abstract}
The advanced technology of microelectromechanical systems (MEMS) makes possible precise and reproducible construction of various microelectrode arrays (MEAs) with patterns of high spatial density. Polymer-based MEMS devices are gaining increasing attention in the field of electrophysiology, since they can be used to form flexible, yet reliable electrical interfaces with the central and the peripheral nervous system. In this paper we present a novel MEA, designed for obtaining neural signals, with a polyimide $(\mathrm{PI})$ - platinum $(\mathrm{Pt})-\mathrm{SU}-8$ layer structure. Electrodes with special, arrow-like shapes were formed in a single row, enabling slight penetration into the tissue. The applied process flow allowed reproducible batch fabrication of the devices with high yield. In vitro characterization of the electrode arrays was performed with electrochemical impedance spectroscopy (EIS) in lactated Ringer's solution. Functional tests were carried out by performing acute recordings on rat neocortex. The devices have proven to be convenient tools for acute in vivo electrocorticography.
\end{abstract}

\section{Introduction}

The advanced technology of microelectromechanical systems (MEMS) makes possible the batch fabrication of miniature custom-made devices with high precision, such as microfabricated electrode arrays, which are commonly utilized for both in vitro (Rousseau et al. 2009) and in vivo (Cheung 2007) electrophysiology. Substrate materials include glass (Kibler et al. 2012) (Lin et al. 2009), silicon (Kawano et al. 2010; Marton et al. 2013; Pongrácz et al. 2013) and titanium (McCarthy et al. 2011). Furthermore, polymers have gained increasing attention in this field, since their production and fabrication costs are relatively low, and their flexibility allows smoother coupling with the soft tissue than rigid substrates (Hassler et al. 2011). Sufficient biocompatibility of the applied materials is also necessary. Several types of polymers, such as SU-8 photoresist (Nemani et al.), Polyimide (PI) (Seymour et al. 2011) and Parylene C (Chang et al. 2007; Rui et al. 2011) meet this criterion. Polymer-based device components for neural interfacing show great heterogeneity in structure and function. Intracranially implantable extracellular probes have been constructed with the use of SU-8 (Altuna et al. 2012), polyimide (PI) (Rousche et al. 2001; Patrick et al. 2006; Cheung et al. 2007) and parylene (Seymour et al. 2011). Flexible cables for data transmission from chronically implanted extracellular probes were developed (Cheng et al. 2013). In order to obtain electrical connection with peripheral nerves, polymer-based sieve (Stieglitz et al. 1997), cuff (Rodriguez et al. 2000) and transverse (Boretius et al. 2010) probes are available. Microfabricated polymer structures are commonly applied for electrocorticography (ECoG) as well (Yeager et al. 2008; Myllymaa et al. 2009; Rubehn et al. 2009; Ochoa et al. 2013), which is a widely used method for the localization of epileptogenic zones (Keene et al. 2000). In this paper, a novel polymer-based microelectrode array is presented, suitable for performing in vivo neuroscientific experiments, e.g. electrocorticography on rats.

\section{Electrode array structure and fabrication}

The microfabricated component of the device is manufactured on an oxidized Si substrate wafer. It consists of a bottom PI layer, a middle metal $\left(\mathrm{TiO}_{\mathrm{x}}+\mathrm{Pt}\right)$ layer and a top SU-8 layer. We have chosen 
this polymer composition in order to exploit the preferential features of the materials: PI sufficiently adheres to the substrate, yet it can be peeled off easily without the necessity of a sacrificial layer, while SU-8 can be conveniently patterned by photolithography, which makes it more suitable for forming the top layer. Two photolithographic masks with resolution of $1 \mu \mathrm{m}$ define the layout, which contains polymer components with lengths of $33.1 \mathrm{~mm}$ and widths of $\mathrm{mm} 8.4 \mathrm{~mm}$ and 24-channel MEAs on their tip. The electrodes are arranged linearly in a single, $1.15 \mathrm{~mm}$ long row. Arrow-shaped recording sites were designed on the edges of microscopic spikes. The sites can be approximated with isosceles triangles with base lengths of $22 \mathrm{um}$ and heights of $20 \mu \mathrm{m}$. The geometric surface area of an electrode is approximately $220 \mu \mathrm{m}^{2}$. This "spiky" geometry was chosen for two main reasons: firstly, in order to allow the electrodes to slightly penetrate into the cortex during in vivo experiments, and secondly to have them located apart from the bulk of the device.

Fig. 1 shows a 3D schematic of the fabrication process. First, a 4-inch double-side polished, (100) oriented Si wafer is cleaned and a $1 \mu \mathrm{m}$ thick thermal silicon-dioxide layer is grown on its sides. Then the wafer is spin-coated by a $7 \mu \mathrm{m}$ thick P84 polyimide layer (step a). The conductive layer, which consists of 30 and $270 \mathrm{~nm}$ thick $\mathrm{TiO}_{\mathrm{x}}$ and Pt layers, respectively, is deposited on the PI layer and patterned by lift-off technique. For this, a $500 \mathrm{~nm}$ thick sacrificial Al layer is deposited before the TiOx/Pt layers by electron beam evaporation and patterned by lithography using a $1.8 \mu \mathrm{m}$-thick Microposit 1818 photoresist layer and wet chemical etching. The $\mathrm{TiO}_{\mathrm{x}}$ is then deposited by reactive sputtering, the purpose of this thin layer is to provide sufficient adhesion. Following this, the Pt layer is sputtered onto the front side as well, and the sacrificial Al layer is etched away, yielding the patterned conductive layer (Fig. 1b). Its different regions will be functioning as electrodes, bonding pads and wiring between them. The process flow is carried on by spin-coating a $20 \mu \mathrm{m}$ thick SU-8 upper insulator layer onto the front side, which is patterned with photolithography (step c). Openings made on the SU-8 layer in this step define the electrodes, bonding pads and the contour lines of the device. The contour line pattern is transferred onto the PI layer by reactive ion etching (RIE) (step d). In this step, the SU-8 is thinned on the top as well, while Pt functions as a masking layer at the electrodes and bonding pads. Hence, the bottom PI layer will be preserved below these structures, providing sufficient mechanical stability for them. Finally, the whole wafer is submerged into distilled water and the thus microfabricated device component can be peeled off from the oxidized Si substrate (step e).

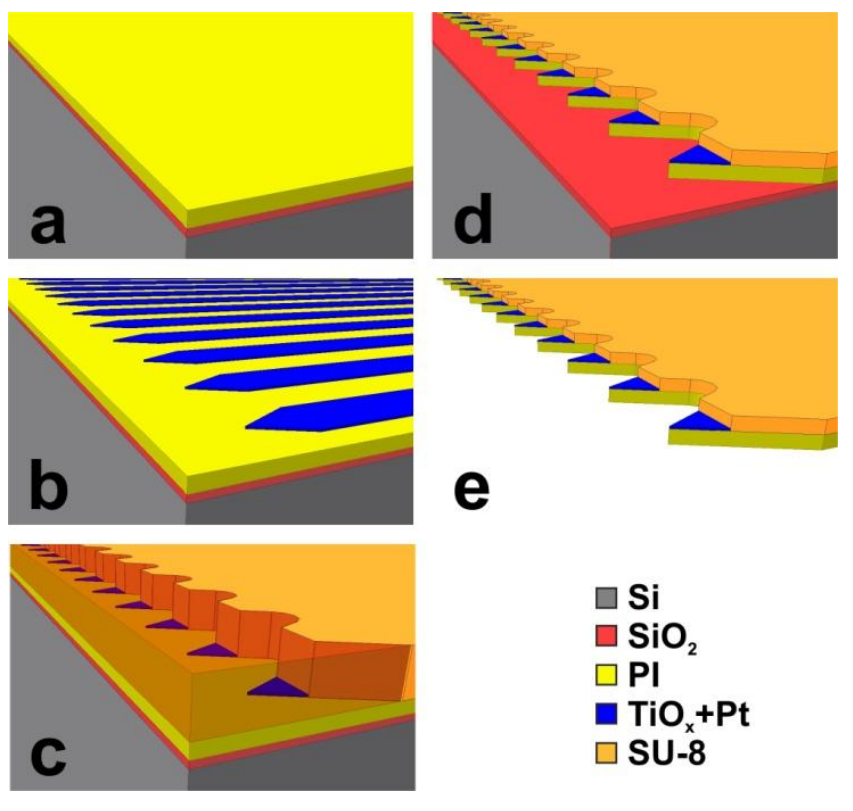


Fig. 1 Schematics of the fabrication process steps. Two photolithographic masks are utilized, the first in step $b$ for pattering the metal layer and the second in step c, for patterning the top SU-8 layer.

The electrode array is electrically and mechanically connected to a custom-made, $1 \mathrm{~mm}$ thick, $10 \mathrm{~mm}$ wide, $127 \mathrm{~mm}$ long printed circuit board (PCB), provided by Auter Ltd. (Budapest, Hungary). Metal pins are soldered to through-hole vias of the PCB and to the bonding pads at the base of the microfabricated component. The PCB is equipped with a Preci-Dip electrical connector for interfacing with the preamplifier. The thus completed device had a width of $10 \mathrm{~mm}$ and a length of $134 \mathrm{~mm}$.

Images of the MEA, prior to bonding to the PCB are shown in Fig. 2a and Fig. $2 b$. The microfabrication process flow was carried out with high yield. Failures, such as imperfections in the pattern of the conductive layer, or tearing the foils while peeling them off of the substrate occurred with a prevalence of less than $10 \%$.

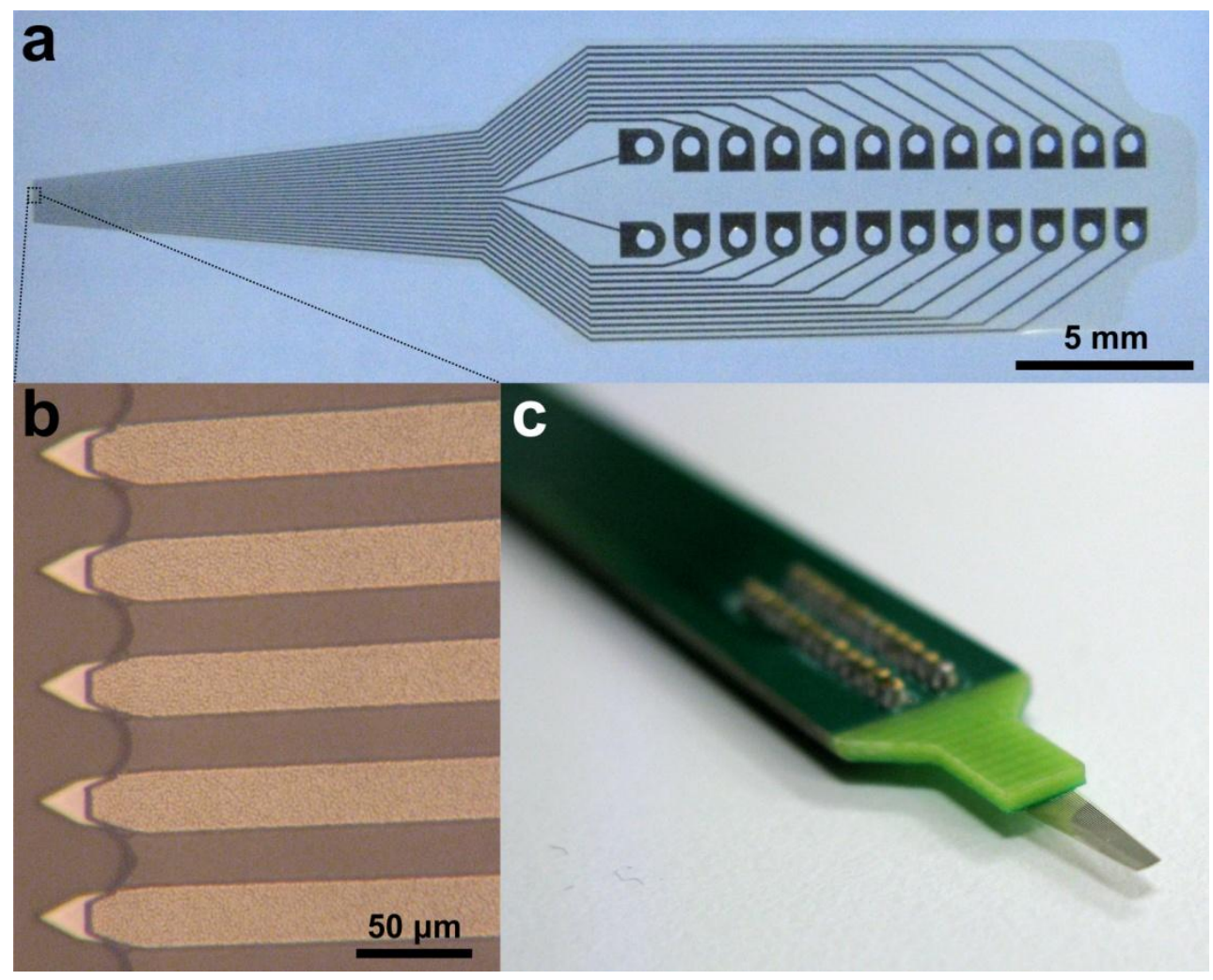

Fig. 2 a The microfabricated component contains with electrodes, corresponding bonding pads and lead wires. The bottom PI and top SU-8 isolating polymer layers are almost totally transparent. $\boldsymbol{b}$ Image of the spiky electrode array at the tip. The center-to center distance of the sensors is 50 $\mu m$. $c$ The microfabricated component mounted on a PCB. The MEMS component is turned over, so the electrode surfaces are facing downwards.

\section{In vitro characterization}

In vitro characterization of the electrodes was performed by electrochemical impedance spectroscopy (EIS), in physiological saline $(0.9 \% \mathrm{w} / \mathrm{v}$ of $\mathrm{NaCl})$, using an $\mathrm{Ag} / \mathrm{AgCl}$ reference electrode (Radelkis Ltd., Hungary) and a counter electrode of platinum wire with relatively high surface area. 
The probe signal was sinusoidal, with an RMS value of $25 \mathrm{mV}$. A Reference 600 instrument (Gamry Instruments, PA, USA) was used as a potentiostat and Gamry Framework 6.02 and Echem Analyst 6.02 software were used for experimental control, data collection and analysis. Experiments were performed in a Faraday cage. Fig. 3 shows the obtained average impedance spectrum of a MEA, following the characteristics of platinum microelectrodes.

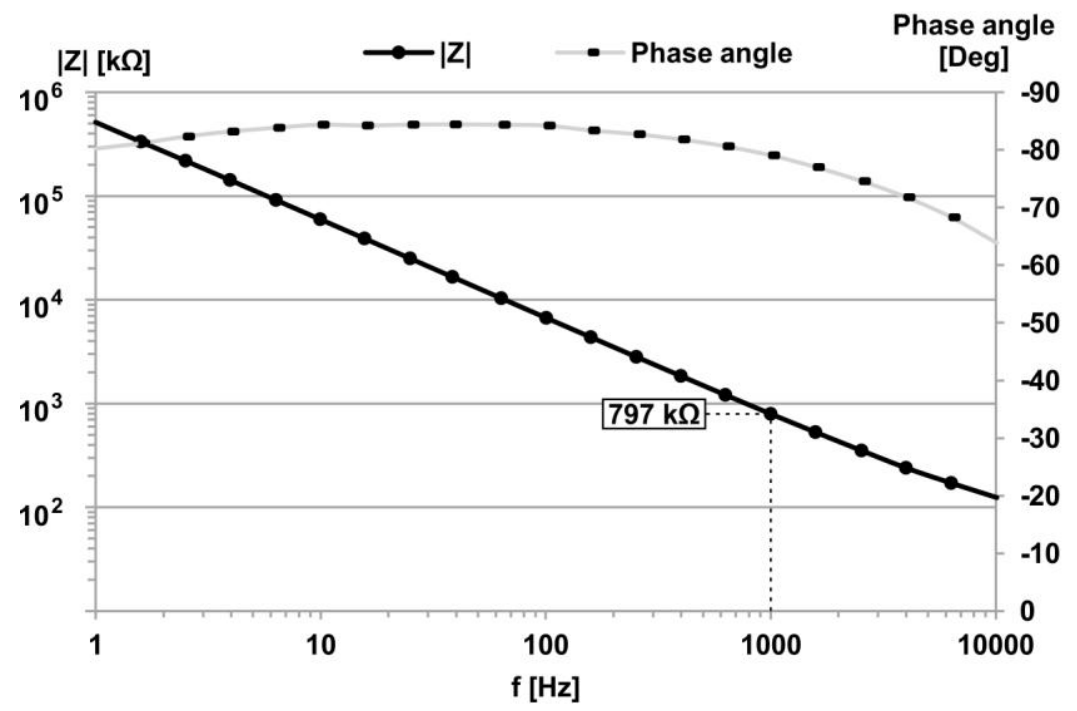

Fig. 3 Bode plot of average electrochemical impedance spectrum of the microelectrodes on a microelectrode array.

\section{In vivo recordings}

In vivo test of the device, functioning as an ECoG has been performed on rat neocortex. All procedures were in accordance with the European Council Directive of 24 November 1986 (86/609/EEC), the Hungarian Animal Act, 1998 and the Animal Care Regulations of the Research Centre for Natural Sciences of the Hungarian Academy of Sciences.

A $260 \mathrm{~g}$ Wistar rat has been anesthetized with $0.5 \mathrm{ml}$ solution of $37.5 \mathrm{mg} / \mathrm{ml}$ ketamine and $5 \mathrm{mg} / \mathrm{ml}$ xylazine, injected intraperitoneally. The same solution was used for maintaining anesthesia throughout the experiment, via intramuscular injections $(0.1 \mathrm{ml} / 30 \mathrm{~min})$. After the initial anesthesia, the rat was fastened in a frame, designed for stereotactic operations (David Kopf). Body temperature was maintained at $37{ }^{\circ} \mathrm{C}$. Craniotomy was performed at $[-1.0 \mathrm{~mm}-4.0 \mathrm{~mm}]$ anterior-posterior (AP), [+1.0 mm $+5.0 \mathrm{~mm}]$ medial-lateral $(\mathrm{ML})$ in reference to the bregma. The MEA was mounted on a micromanipulator. The microdevice was adjusted into a transverse plane, its longitudinal axis was perpendicular to the surface of the neocortex. The spiky tips, containing the electrodes were submerged into the tissue and brain signals were recorded. This procedure was performed at several locations in the craniotomy window. Figure 4 demonstrates the placement of the MEA during a recording. 


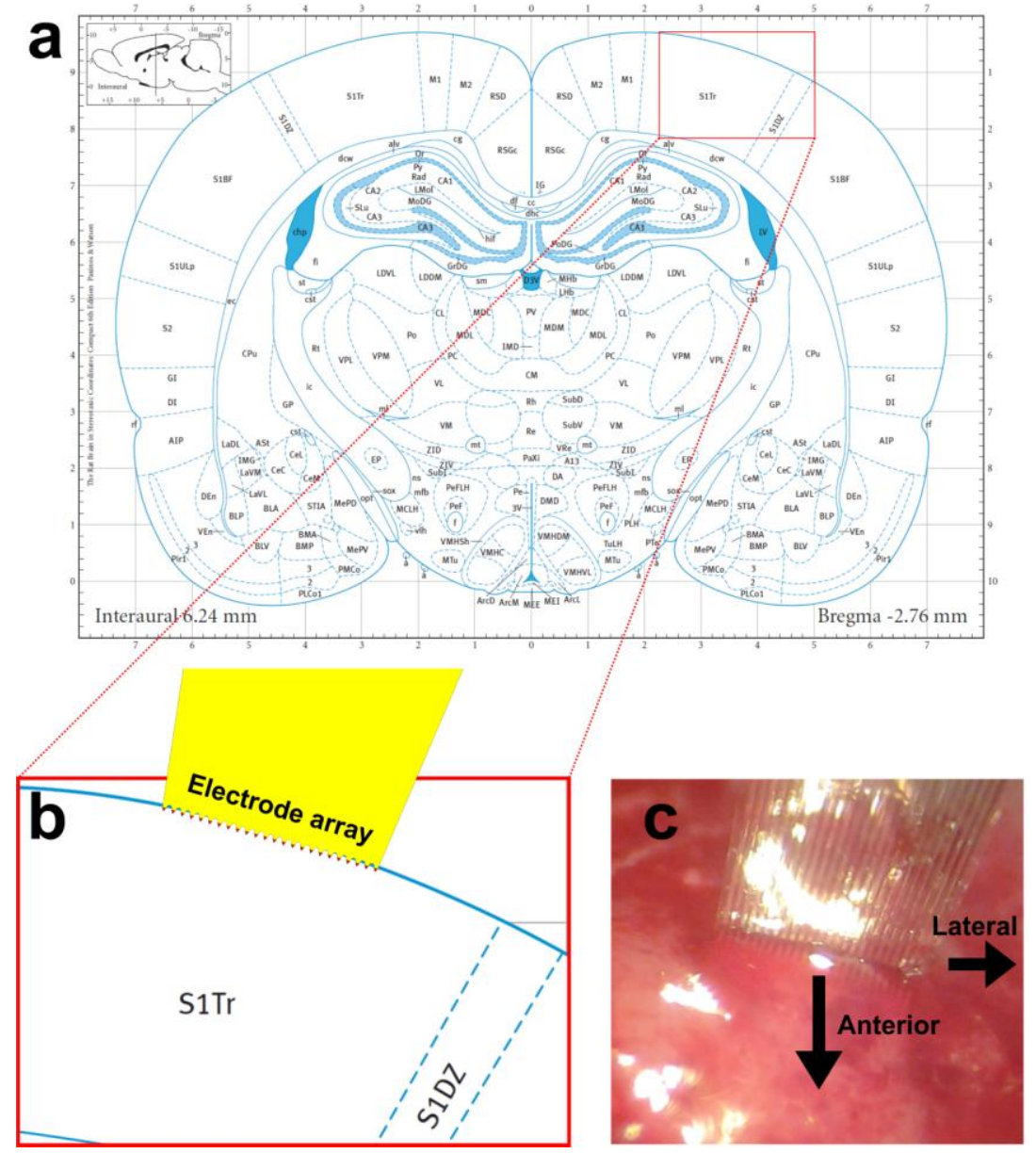

Fig. 4 a Coronal section of the rat brain $-2.76 \mathrm{~mm}$ posterior to the bregma. Illustration is based on Figure 56 of (Paxinos \& Watson 2009). b Zoomed view of a somatosensory area and a proportional representation of the MEA on the cortex. $c$ Microscopic image the of vivo use of the device.

The signals were recorded using an amplifier and a data acquisition system with 23 sensor channels and a $24^{\text {th }}$ channel, allocated for providing trigger signals. The electrical activity was recorded with $20 \mathrm{kHz}$ sampling rate, 16 bit resolution and a gain of 1000 (Ulbert et al. 2001). The thus obtained waveforms were visualized and analyzed off-line with NeuroScan 4.5 software (Compumedics, El Paso, TX).

Fig. 5 shows waveforms of a representative in vivo recording above the somatosensory cortex. An oscillation of approximately $1.6 \mathrm{~Hz}$ is visible on all of the sensor channels. Such slow oscillation is the result of ketamine-xylazine anesthesia (Steriade et al. 1993; Fontanini et al. 2003). Comparing them to each other, a divergence is observable in the waveforms, showing the spatial variation of the LFP in the cortex along the $1.2 \mathrm{~mm}$ length of the array. The experiment was performed as a proof of concept for the MEA, further investigation on the physiological causes of the waveforms exceeds the scope of this study. We have found that the microdevice tolerated these measurements without noticeable deterioration. 


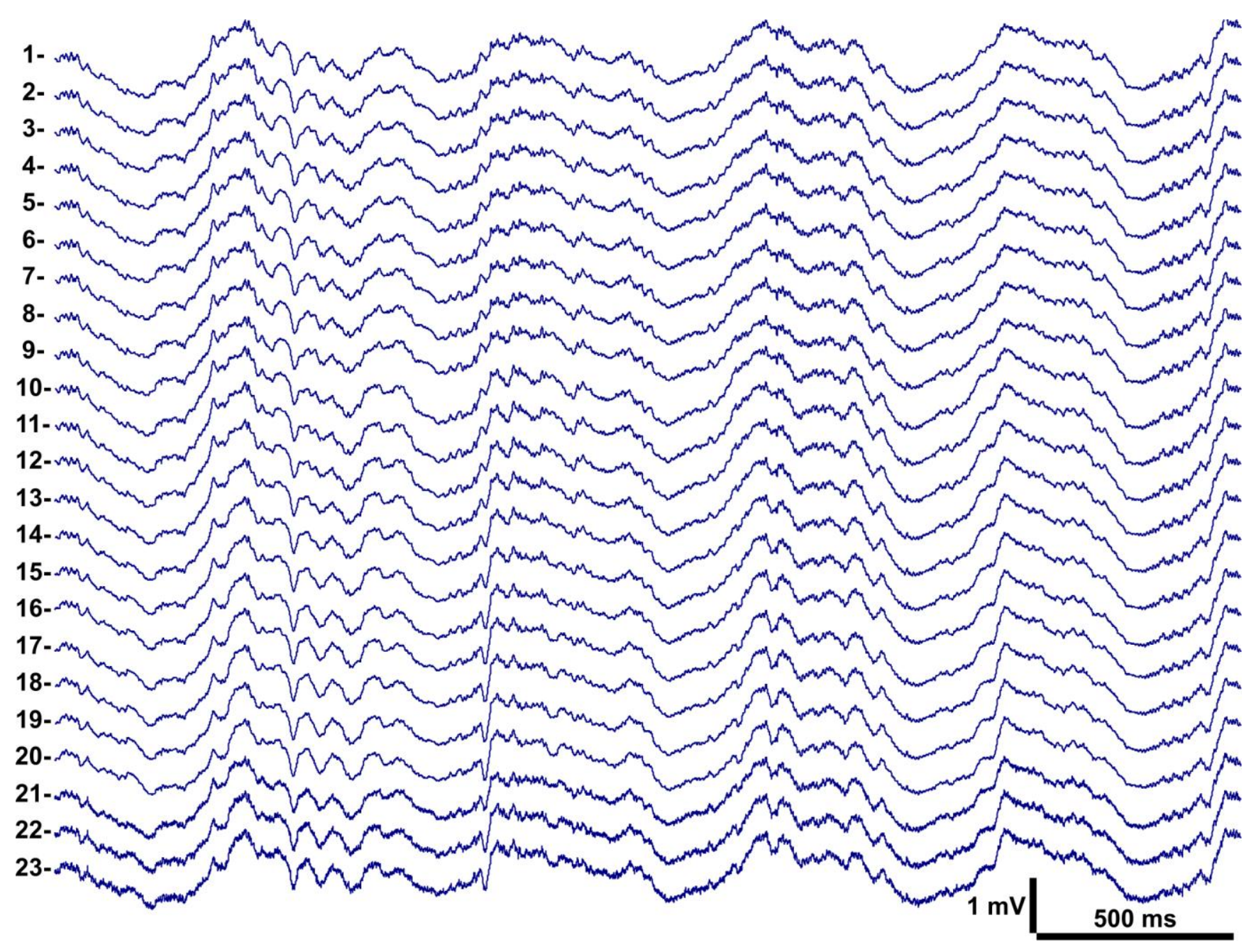

Fig. 5 Representative electrophysiological signals obtained from in vivo experiments on rat neocortex. The frequency of the slow oscillation is approximately $1.6 \mathrm{~Hz}$, indicating a state of slow-wave sleep, caused by ketamine - xylazine anesthesia.

Noise measurements were performed in physiological saline $(0.9 \% \mathrm{w} / \mathrm{v}$ of $\mathrm{NaCl})$, using the same electrode and recording system that was used for the in vivo studies. The solution was heated to approximately $38^{\circ} \mathrm{C}$ with a heating pad. Fig. 6 shows a representative in vivo waveform and the noise of a channel, measured in saline. Using the thus obtained data, the RMS noise of the electrodes was estimated, which was $8.71 \mu \mathrm{V}$ on the average. Taking into consideration the changes of the measured local field potentials (LFP), with RMS values in the range of 300-400 $\mu \mathrm{V}$, we can assume that the noise does not compromise LFP measurements. However, the signals of single unit activities, i.e. spikes, which are in the range of tens of $\mu \mathrm{Vs}$, can be suppressed by such a noise. For measuring such low-amplitude signals, noise reduction would be necessary. It could be achieved by increasing the effective surface area of the microelectrodes (Heim et al. 2012), e.g. by electrolytic deposition of platinum (Marton et al. 2014). 


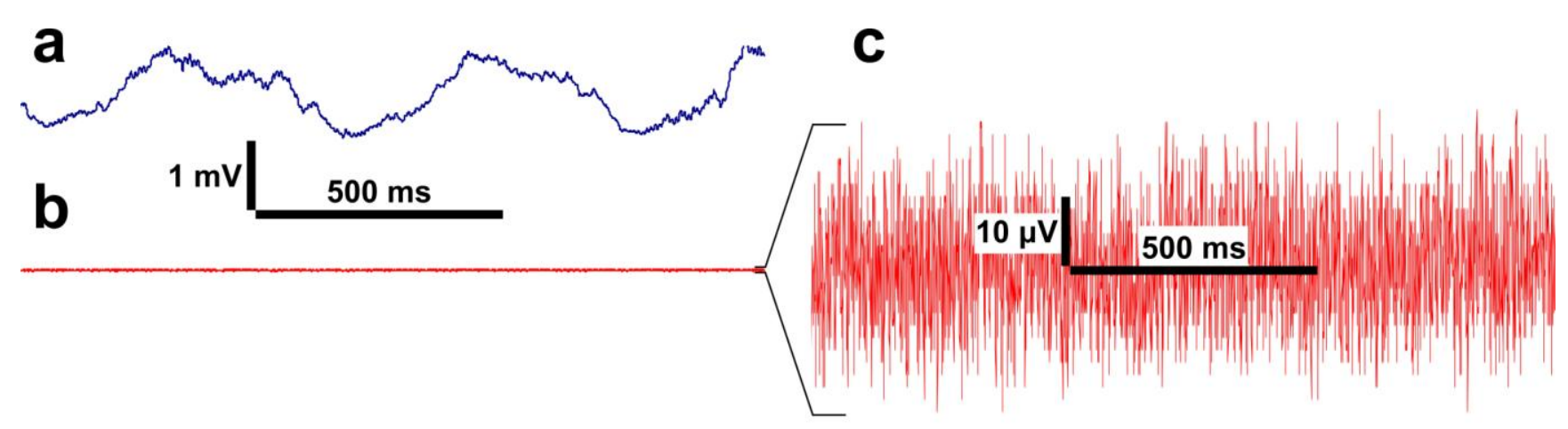

Fig. 6 a In vivo cortical recording. b Noise measured in physiological saline with the same electrode and recording system (same scale). c Zoomed view of the noise (y scale reduced to 1\%)

\section{Conclusions}

We have manufactured MEAs with PI bottom insulator, TiOx + Pt conductive and SU-8 top insulator layers and found that this structure of microfabricated layers allows a rapid and reliable technological process flow. Acute in vivo functional tests on rat cortex were performed. The 24 electrodes cover a $1.15 \mathrm{~mm}$ long linear section of the tissue, thus they make possible obtaining detailed electrophysiological recordings of a small area, containing neighboring cortical columns. The polymer-based device is not so stiff and fragile as silicon-based neural probes, however, due to its relatively wide shaft, it is not suitable for implantation into deep areas. The arrow-like electrodes protruding from the shank allow a slight penetration into the tissue, which is not typical of commonly used polymer-based ECoGs. On the other hand, this feature makes our device more invasive compared to them. The $27 \mu \mathrm{m}$ thick PI-SU8 layer composition at the bulk of the device and the single $7 \mu \mathrm{m}$ thick PI layer beneath the electrodes have proven to be able to provide sufficient mechanical robustness for the electrode array to endure interfacing with the neural tissue.

\section{Acknowledgements}

We wish to thank Mrs. Károlyné Payer, Mr. Róbert Hodován and Mr. András Lőrincz for their support in microfabrication. We are also grateful to Attila Nagy for his help with packaging. This work was funded by the Bolyai János Grant of the HAS to Anita Pongrácz and the OTKA K81354, TIA_13_NA PAIV/ 1-2-3-6, ANR-TÉT Multisca, TAMOP-4.2.1.B-11/2/KMR-2011- 0002 grants to István Ulbert.

\section{References}


Altuna A., Menendez de la Prida L., Bellistri E., Gabriel G., Guimerá A., Berganzo J., Villa R. \& Fernández L.J. (2012) SU-8 based microprobes with integrated planar electrodes for enhanced neural depth recording. Biosensors and Bioelectronics 37, 1-5.

Boretius T., Badia J., Pascual-Font A., Schuettler M., Navarro X., Yoshida K. \& Stieglitz T. (2010) A transverse intrafascicular multichannel electrode (TIME) to interface with the peripheral nerve. Biosensors and Bioelectronics 26, 62-9.

Chang T.Y., Yadav V.G., De Leo S., Mohedas A., Rajalingam B., Chen C.L., Selvarasah S., Dokmeci M.R. \& Khademhosseini A. (2007) Cell and protein compatibility of parylene-C surfaces. Langmuir 23, 11718-25.

Cheng M.-Y., Park W.-T., Yu A., Xue R.-F., Tan K., Yu D., Lee S.-H., Gan C. \& Je M. (2013) A flexible polyimide cable for implantable neural probe arrays. Microsystem Technologies 19, 1111-8.

Cheung K.C. (2007) Implantable microscale neural interfaces. Biomed Microdevices 9, 923-38.

Cheung K.C., Renaud P., Tanila H. \& Djupsund K. (2007) Flexible polyimide microelectrode array for in vivo recordings and current source density analysis. Biosensors and Bioelectronics 22, 1783-90.

Fontanini A., Spano P. \& Bower J.M. (2003) Ketamine-xylazine-induced slow ( $<1.5 \mathrm{~Hz}$ ) oscillations in the rat piriform (olfactory) cortex are functionally correlated with respiration. $J$ Neurosci 23, 7993-8001.

Hassler C., Boretius T. \& Stieglitz T. (2011) Polymers for neural implants. Journal of Polymer Science Part B: Polymer Physics 49, 18-33.

Heim M., Yvert B. \& Kuhn A. (2012) Nanostructuration strategies to enhance microelectrode array (MEA) performance for neuronal recording and stimulation. J Physiol Paris 106, 137-45.

Kawano T., Harimoto T., Ishihara A., Takei K., Kawashima T., Usui S. \& Ishida M. (2010) Electrical interfacing between neurons and electronics via vertically integrated sub-4 micromdiameter silicon probe arrays fabricated by vapor-liquid-solid growth. Biosens Bioelectron 25, 1809-15.

Keene D.L., Whiting S. \& Ventureyra E.C. (2000) Electrocorticography. Epileptic Disord 2, 57-63.

Kibler A.B., Jamieson B.G. \& Durand D.M. (2012) A high aspect ratio microelectrode array for mapping neural activity in vitro. J Neurosci Methods 204, 296-305.

Lin C.-W., Lee Y.-T., Chang C.-W., Hsu W.-L., Chang Y.-C. \& Fang W. (2009) Novel glass microprobe arrays for neural recording. Biosensors and Bioelectronics 25, 475-81.

Marton G., Bakos I., Fekete Z., Ulbert I. \& Pongracz A. (2014) Durability of high surface area platinum deposits on microelectrode arrays for acute neural recordings. J Mater Sci Mater Med 25, 931-40.

Marton G., Fekete Z., Fiath R., Baracskay P., Ulbert I., Juhasz G., Battistig G. \& Pongracz A. (2013) In Vivo Measurements With Robust Silicon-Based Multielectrode Arrays With Extreme Shaft Lengths. Sensors Journal, IEEE 13, 3263-9.

McCarthy P.T., Otto K.J. \& Rao M.P. (2011) Robust penetrating microelectrodes for neural interfaces realized by titanium micromachining. Biomed Microdevices 13, 503-15.

Myllymaa S., Myllymaa K., Korhonen H., Töyräs J., Jääskeläinen J.E., Djupsund K., Tanila H. \& Lappalainen R. (2009) Fabrication and testing of polyimide-based microelectrode arrays for cortical mapping of evoked potentials. Biosensors and Bioelectronics 24, 3067-72.

Nemani K.V., Moodie K.L., Brennick J.B., Su A. \& Gimi B. In vitro and in vivo evaluation of SU-8 biocompatibility. Materials Science and Engineering: $C$.

Ochoa M., Wei P., Wolley A.J., Otto K.J. \& Ziaie B. (2013) A hybrid PDMS-Parylene subdural multielectrode array. Biomed Microdevices 15, 437-43.

Patrick E., Ordonez M., Alba N., Sanchez J.C. \& Nishida T. (2006) Design and fabrication of a flexible substrate microelectrode array for brain machine interfaces. Conf Proc IEEE Eng Med Biol Soc 1, 2966-9.

Paxinos G. \& Watson C. (2009) The rat brain in stereotaxic coordinates: compact sixth edition. Academic Press. 
Pongrácz A., Fekete Z., Márton G., Bérces Z., Ulbert I. \& Fürjes P. (2013) Deep-brain silicon multielectrodes for simultaneous in vivo neural recording and drug delivery. Sensors and Actuators B: Chemical 189, 97-105.

Rodriguez F.J., Ceballos D., Schuttler M., Valero A., Valderrama E., Stieglitz T. \& Navarro X. (2000) Polyimide cuff electrodes for peripheral nerve stimulation. J Neurosci Methods 98, 105-18.

Rousche P.J., Pellinen D.S., Pivin D.P., Jr., Williams J.C., Vetter R.J. \& kirke D.R. (2001) Flexible polyimide-based intracortical electrode arrays with bioactive capability. Biomedical Engineering, IEEE Transactions on 48, 361-71.

Rousseau L., Lissorgues G., Verjus F. \& Yvert B. (2009) Microfabrication of high-density microelectrode arrays for in vitro applications. In: 13th International Conference on Biomedical Engineering (eds. by Lim C \& Goh JH), pp. 790-3. Springer Berlin Heidelberg.

Rubehn B., Bosman C., Oostenveld R., Fries P. \& Stieglitz T. (2009) A MEMS-based flexible multichannel ECoG-electrode array. J Neural Eng 6, 1741-2560.

Rui Y., Liu J., Wang Y. \& Yang C. (2011) Parylene-based implantable Pt-black coated flexible 3-D hemispherical microelectrode arrays for improved neural interfaces. Microsystem Technologies 17, 437-42.

Seymour J.P., Langhals N.B., Anderson D.J. \& Kipke D.R. (2011) Novel multi-sided, microelectrode arrays for implantable neural applications. Biomed Microdevices 13, 441-51.

Steriade M., Nunez A. \& Amzica F. (1993) A novel slow ( $1 \mathrm{~Hz}$ ) oscillation of neocortical neurons in vivo: depolarizing and hyperpolarizing components. J Neurosci 13, 3252-65.

Stieglitz T., Beutel H. \& Meyer J.U. (1997) A flexible, light-weight multichannel sieve electrode with integrated cables for interfacing regenerating peripheral nerves. Sensors and Actuators $A$ : Physical 60, 240-3.

Ulbert I., Halgren E., Heit G. \& Karmos G. (2001) Multiple microelectrode-recording system for human intracortical applications. J Neurosci Methods 106, 69-79.

Yeager J.D., Phillips D.J., Rector D.M. \& Bahr D.F. (2008) Characterization of flexible ECoG electrode arrays for chronic recording in awake rats. J Neurosci Methods 173, 279-85. 